\title{
TECNOLOGIAS DO NOVO LAMINADOR DE CHAPAS GROSSAS DA GERDAU*
}

\author{
Rafael Abreu Fraga ${ }^{1}$ \\ Rodney Pardo Alves ${ }^{2}$ \\ Flávio Viana de Freitas ${ }^{3}$ \\ Emanuelle Garcia Reis ${ }^{4}$ \\ Maurício Martins Pereira \\ José Herbert Dolabela da Silveira ${ }^{6}$
}

\section{Resumo}

Em qualquer novo investimento, o desafio é ter um projeto com uma fábrica com flexibilidade para produzir uma ampla gama de produtos de alto valor agregado para atender a demandas futuras dos setores de energia, naval, construção e equipamentos pesados. O emprego de equipamentos robustos com elevado nível de automação é fundamental para isso. Um componente chave é a utilização da laminação totalmente automática através de modelos físicos integrados com o controle dos equipamentos e das temperaturas de processo objetivando alcançar patamares diferenciados de produtividade e qualidade. Este trabalho visa apresentar os novos recursos técnológicos incorporados a nova linha de Laminação de Chapas Grossas da Gerdau em Ouro Branco/MG;

Palavras-chave: Laminação de chapas grossas; Tecnologia; Automação.

\section{Abstract}

\section{LATEST TECHNOLOGIES OF NEW GERDAU PLATE MILL}

As the economic conditions remain unpredictable, the heavy plate market comes facing challenges unimaginable in the global scenario. In any new investment, the challenge and designing a plant with flexibility to produce a wide range of high valueadded products to answer a future demands of energy sectors, shipbuilding, construction and heavy equipment. The robust equipment combination with high automation level of and fundamental for this. A key component and the use of fully automatic rolling with physical models integrated to the control of equipment and process temperatures in order to reach the best in mechanical properties. This paper presents new technological features incorporated into the new Gerdau Heavy Plate in Ouro Branco city, Brazil

Key Words: Plate mill; Technologies; Automation.

1 Sócio da ABM, Engenheiro Metalurgista, M.B.A.- Assessor Técnico da Laminação de Chapas Grossas da Gerdau.

2 Sócio da ABM, Engenheiro Metalurgista, M.B.A.- Chefe de Área da Laminação de Chapas Grossas da Gerdau.

3 Sócio da ABM, Engenheiro Metalurgista, M.B.A.- Assessor Técnico da Laminação de Chapas Grossas da Gerdau.

4 Sócia da ABM, Engenharia Civil, M.Eng - Assessor Técnico da Laminação de Chapas Grossas da Gerdau.

5 Sócio da ABM, Engenheiro Metalurgista, M.B.A.- Assessor Técnico da Laminação de Chapas Grossas da Gerdau.

6 Sócio da ABM, Engenheiro Metalurgista, M.Eng., M.B.A, - Gerente da Laminação de Chapas Grossas da Gerdau. 


\section{INTRODUÇÃO}

A Gerdau mostra neste trabalho as mais recentes tecnologias empregadas no maior investimento de sua centenária história que é a nova linha de Laminação de Chapas Grossas em Ouro Branco - MG, visando atender as mais exigentes especificações do mercado brasileiro e mundial através da obtenção de produtos com excelente homogeneidade de propriedades mecânicas, planicidade e uniformidade de espessura.

Os produtos serão destinados principalmente à fabricação de produtos para aplicação nos setores de geração de energia, construção civil, maquinários pesados, naval e vasos de pressão. Além disso, a Gerdau visa atuar no iminente mercado de óleo e gás, estando preparada para atender às demandas que serão geradas pelos investimentos nesse setor no Brasil e no mundo.

\section{DESENVOLVIMENTO}

O portfólio de produtos atinge um novo patamar com o recém-inaugurado Laminador de Chapas Grossas, um dos mais modernos em operação no mundo. Atuando de forma integrada em todas as etapas do processo esta nova linha de produção é capaz de oferecer chapas de altíssima resistência, qualidade e produtividade inéditas no país. Isso só foi possível através dos inovadores recursos tecnológicos que estão embarcados nos principais equipamentos da linha de laminação fornecidos pela Primetals Technologies. A seguir, pontuamos os principais itens de cada equipamento da linha de laminação.

\subsection{LAMINADOR}

O laminador de Chapas Grossas possui o chamado "Estado da Arte" em equipamentos e recursos tecnológicos: uma cadeira de alta capacidade de carga com baixa cedagem, modelos matemáticos integrados para controle planicidade, temperatura, forma e propriedades mecânicas;

Com relação ao controle de espessura a manutenção da espessura constante em todo o esboço é um dos maiores desafios de um laminador desse porte. Principalmente nas extremidades do esboço onde, sabidamente, o material está mais frio e resistente, a homogeneidade de espessura em relação ao corpo se torna mais crítica. O modelo matemático do esquema de passes calcula múltiplos setpoints ao longo do comprimento do esboço a cada passe de laminação (figura 1).

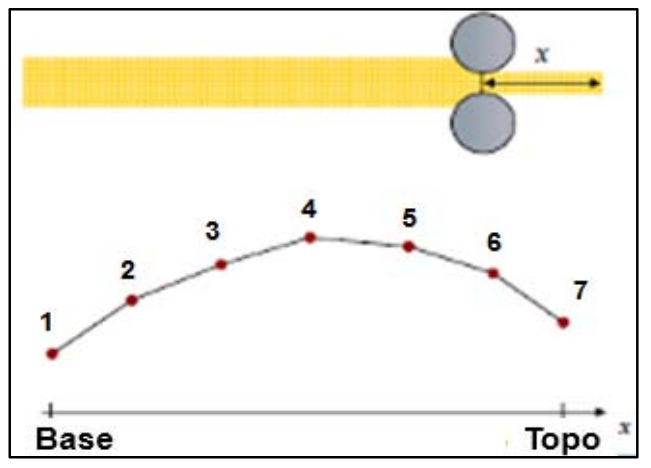

Figura 1 - Múltiplos setpoints
A função AGC complementa o modelo e mantém a espessura constante ao longo do esboço absorvendo e compensando as variações de força em decorrência da variação do desgaste, expansão térmica e flexão dos cilindros de trabalho, filme de óleo e excentricidade dos cilindros de encosto;

Em modo Gauge Meter a deformação real do laminador é calculada e comparada com a cedagem da cadeira para compensar o gap; 
Desta maneira o gap é mantido constante independente da força de laminação. Para que tudo isso aconteça o tempo de resposta dos atuadores (HAGC) é fundamental para que as correções aconteçam no exato ponto da sua necessidade.

As cápsulas hidráulicas do laminador da Gerdau são do tipo "curso longo" possuem tempo de resposta inferior a $30 \mathrm{~ms}$ para um degrau de $100 \mu \mathrm{m}$ e precisão de posicionamento inferior $15 \mu \mathrm{m}$. As mesmas estão localizadas na parte inferior da cadeira de laminação. Desta forma as cápsulas também desempenham a função de ajuste automático da altura da linha de passe (pass line) minimizando a geração de pontas altas ou baixa durante a laminação. A figura 2 ilustra o posicionamento e a capsula do HAGC do laminador.

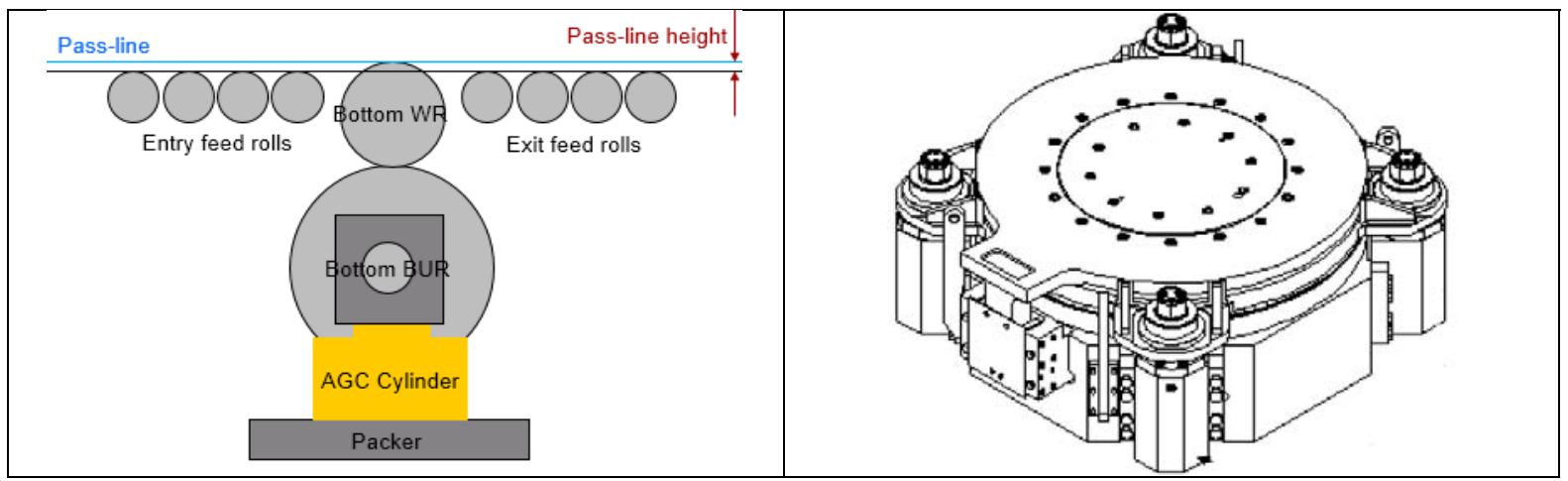

Figura 2 - Posição das Cápsulas hidráulicas do laminador

Outra função desempenhada pela combinação HAGC e Modelo Matemático é o controle automático do formato do esboço denominado PVPC $®$ - Plan View Pattern Control. Essa funcionalidade é um diferencial do laminador da Gerdau e tem como principal objetivo o aumento do rendimento metálico do processo de laminação com consequente redução dos custos de produção.

Quando uma placa é processada no laminador ocorre a tendência de produzirmos esboços com espalhamento de material no topo e na base, conforme figura 3 , abaixo.

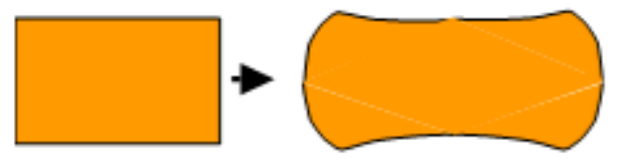

Figura 3 - Espalhamento de material nas extremidades

Dependendo da direção de laminação, teremos dois formatos específicos: se a laminação se der no sentido longitudinal (sem giros) teremos a forma denominada "osso de cachorro" se a laminação se der no sentido transversal teremos a forma denominada "barril". Quando a laminação ocorre parcialmente em ambos os sentidos teremos um formato misto entre as duas formas. A forma que irá predominar dependerá do índice de alargamento ( $\mathrm{IA}=$ largura de esboço/largura de placa). A figura 4 exemplifica essa correlação: 


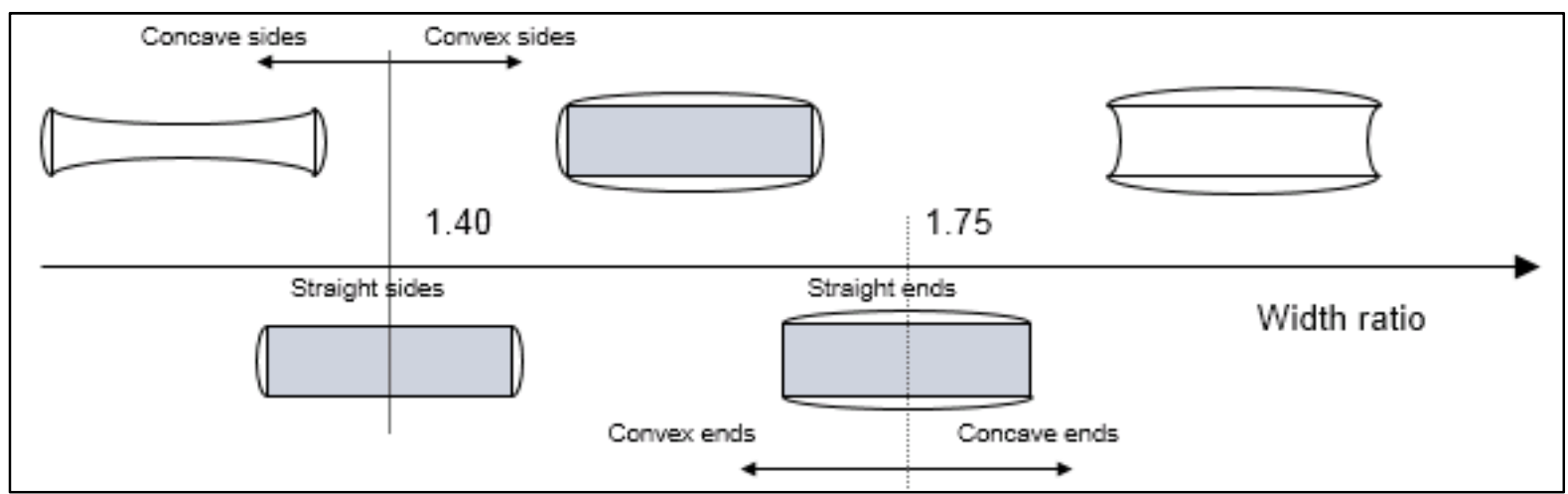

Figura 4 - Correlação do índice de alargamento e o formato do esboço

Para prevenir a formação dessas irregularidades são aplicados a determinados passes um perfil variável de espessura. Essa função faz parte do cálculo do esquema de passes e atua no primeiro passe longitudinal no último passe transversal visando promover um perfil variável de espessura em ambos os sentidos. A figura 5 , ilustra os passes onde são aplicados o perfil variável de espessura para controle do formato do esboço:

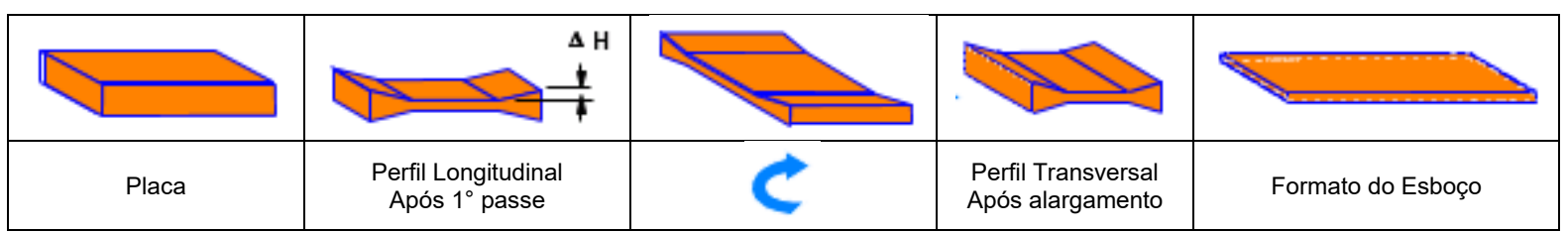

Figura 5 - Passes com PVPC para controle da forma do laminado

Por fim, o HAGC ainda possui a função RAC® - Rolls Alignment Control ou nivelamento automático dos cilindros de trabalho. Essa tem por finalidade compensar o diferencial de força entre os lados da cadeira de laminação pelo movimento em forma de "gangorra" do curso das cápsulas do HAGC. Isso faz com que tenhamos sempre os cilindros paralelos entre si, evitando a ocorrência de desnivelamentos ou camber no material laminado.

A figura 6 mostra a atuação do RAC dado um diferencia de força que surgiu durante o passe de laminação:

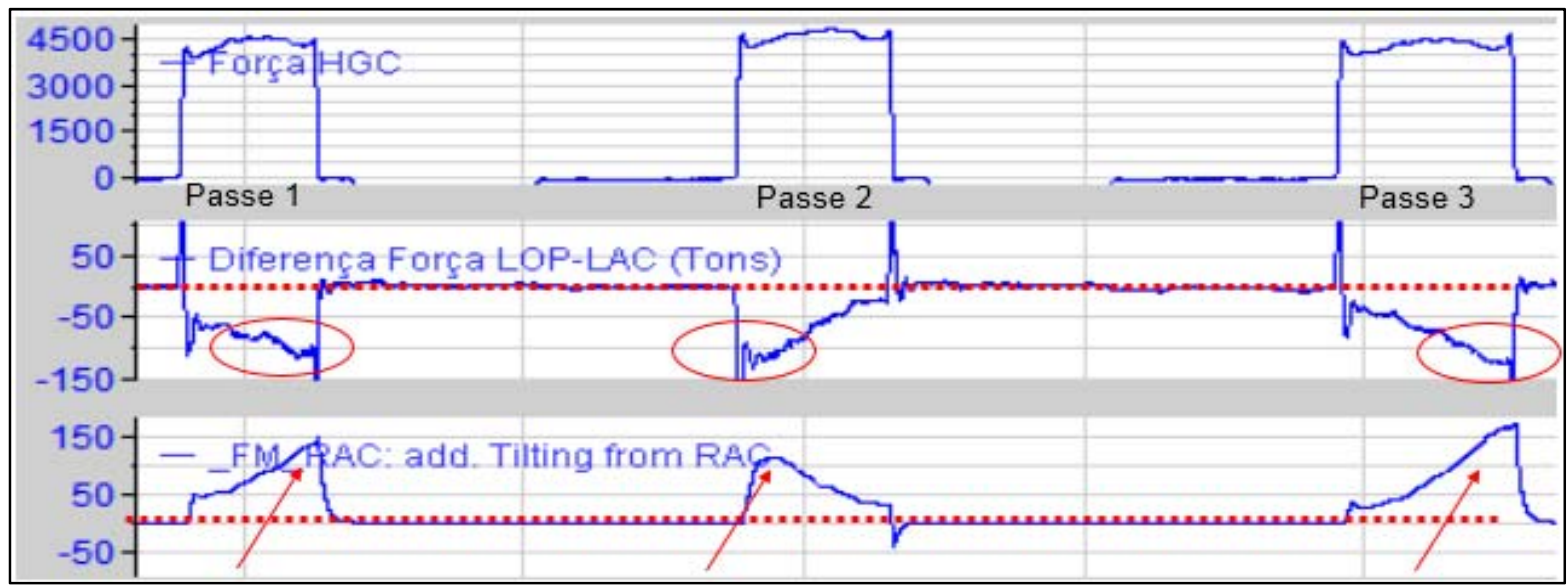

Figura 6 - Passes com força diferencial e atuação do RAC no sentido oposto a diferença de carga 


\section{Controle de Propriedades Mecânicas}

Um critério decisivo para a qualidade dos produtos laminados a quente são as propriedades mecânicas especificadas pelo cliente, especialmente para a resistência à tração e de escoamento.

Para atestar essa qualidade, tradicionalmente retiram-se amostras para realizar uma série de testes que são caros e demorados. Para superar essas deficiências, um Modelo de Monitoramento de Microestrutura foi integrado aos demais modelos da linha. Em resumo, o modelo controla os parâmetros on-line durante o processo de produção e solta como resultado uma previsão de propriedades mecânicas o que minimiza os ensaios em laboratorios encurtando o tempo de liberação de forma significativa. A figura 7 abaixo exemplifica essa integração:

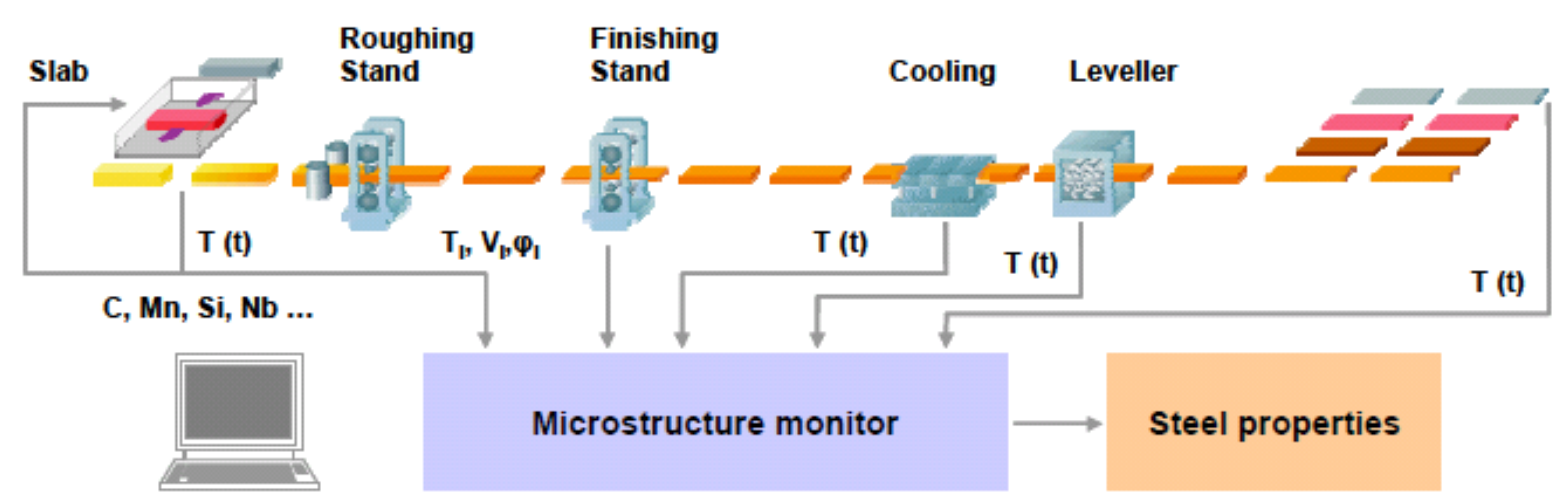

Figura 7 - Integração do sistema em todas as etapas do processo de laminação

A figura 8 mostra os dados de entrada/saída do modelo bem como o acerto das propriedades mecânicas

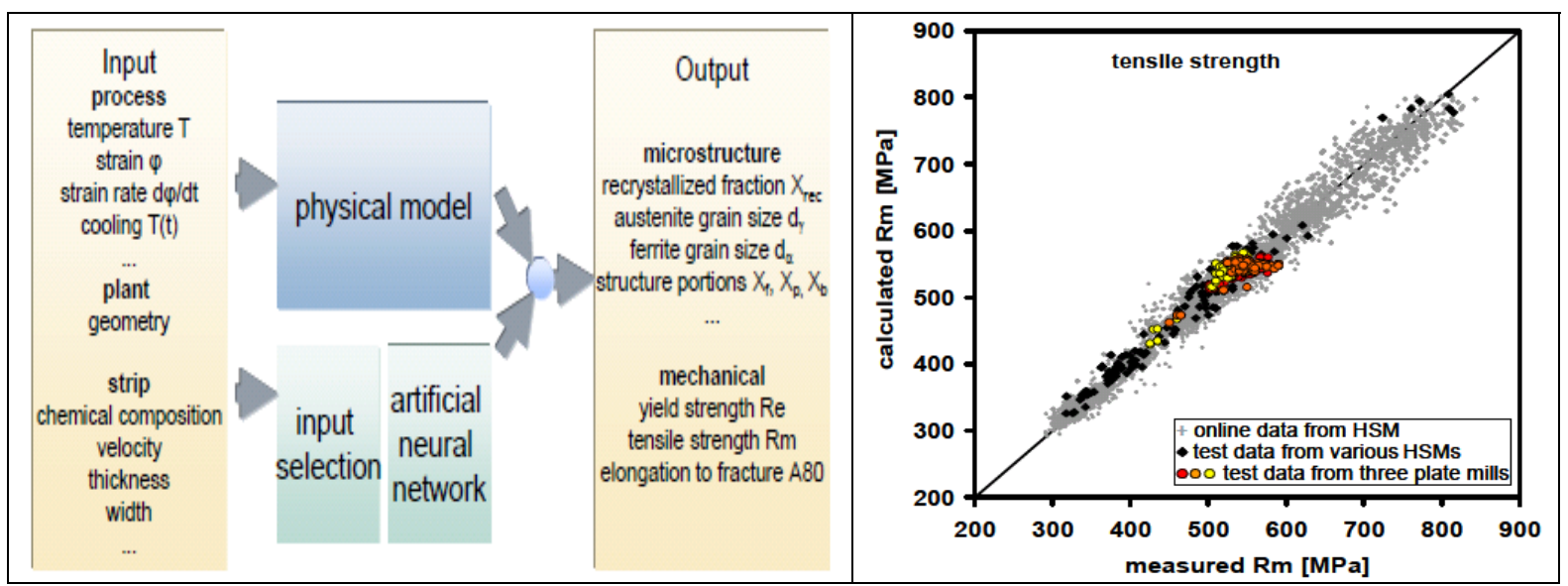

Figura 8 - Dados de entrada e saída do modelo e acerto de propriedades mecânicas

\section{Controle de Planicidade}

Um dos maiores problemas na laminação é a tendência de ocorrência de problemas com distorções da planicidade, principalmente em materiais de espessura fina. A planicidade da chapa depende das mudanças de perfil durante o passe de laminação. Se o perfil transversal relativo não muda, teremos uma chapa plana. Em regras gerais se reduzirmos a coroa durante o passe teremos ondulação central e se aumentarmos 
a coroa durante o passe teremos ondulação lateral. A figura 9 abaixo retrata os perfis de entrada e saída de um passe e a forma resultante:
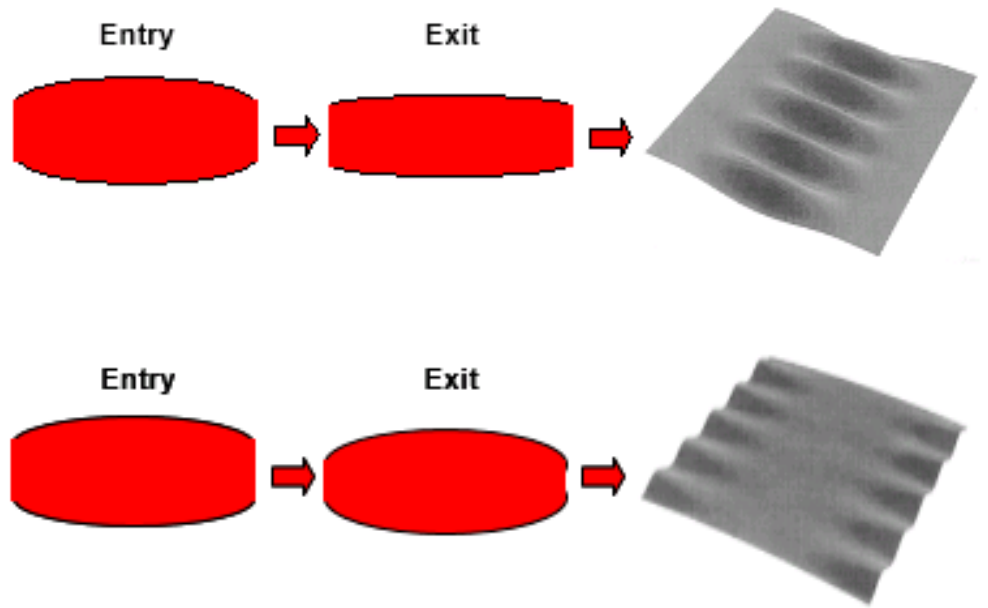

Figura 9 - Relação do perfil de entrada/saída do passe e a forma resultante

Para prevenir a ocorrência de ondulações um critério da equação abaixo, representado na figura 10 , deve ser respeitado:

$$
-80\left(\frac{h_{0}}{w}\right)^{\mathbf{y}}<\left(\frac{C_{i}}{h_{i}}-\frac{C_{0}}{h_{0}}\right)<40\left(\frac{h_{0}}{w}\right)^{\mathbf{y}}
$$

Onde;

$h_{\circ}=$ Espessura Saída

$h_{i}=$ Espessura Entrada

$\mathrm{C}_{\mathrm{o}}=$ Perfil Saída Passe

$\mathrm{C}_{\mathrm{i}}=$ Perfil Entrada Passe

$\mathrm{W}=$ Largura chapa

$y=1.86$

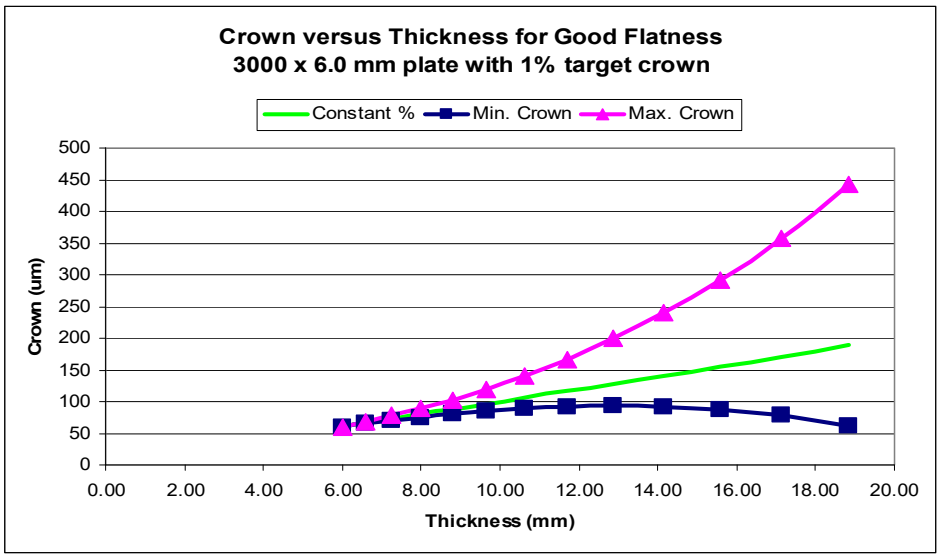

Figura 10 - Critério para obtenção de planicidade

Ou seja, para obtenção de planicidade é fundamental o controle do perfil da chapa. 0 laminador de Chapas Grossas possuí atuadores capazes de manter o perfil constante em todos os passes mesmo sob condições severas de laminação (força alta e temperaturas baixas). O WRB - Work Roll Bending e o WRS - Work Roll Shifting combinados com o perfil SmartCrown ${ }^{\circledR}$ dos cilindros de trabalho ajustam o perfil da chapa pela mudança da posição relativa entre os cilindros de trabalho antes de cada passe. O modelo matemático calcula a relação entre a mudança na força de laminação e a mudança da flexão dos cilindros para permitir correções dinâmicas durante o passe. Combinados, SmartCrown e Work Roll Bending garantem a obtenção da planicidade da chapa dentro de critérios mais rigorosos de planicidade como mostra a figura 11 abaixo: 


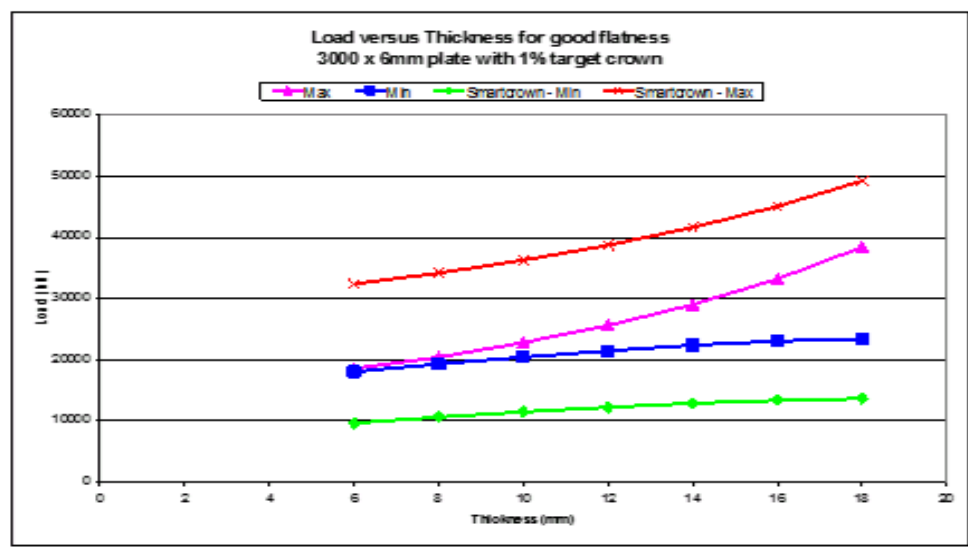

Figura 11 - Critério para obtenção de planicidade expandido

A posição do WRS com Smart Crown® é calculado pelo modelo matemático como parte do esquema de passes, objetivando a manutenção do perfil transversal sem o uso do WRB. Isso permite o uso pleno do WRB durante o passe.

\section{Chapas com Múltiplas Espessuras}

Outra inovação tecnológica proporcionada pelo dueto modelo/HAGC é a laminação de chapas com múltiplas espessuras ao longo do comprimento da chapa. Essas chapas são aplicadas principalmente nos setores naval e construção de grandes estruturas metálicas como pontes. Os principais benefícios para o cliente são a redução de custos com soldagem e uniões e rapidez na montagem. A figura 12 mostra alguns dos perfis de espessura ao longo do comprimento da chapa possíveis de serem obtidos [2]:

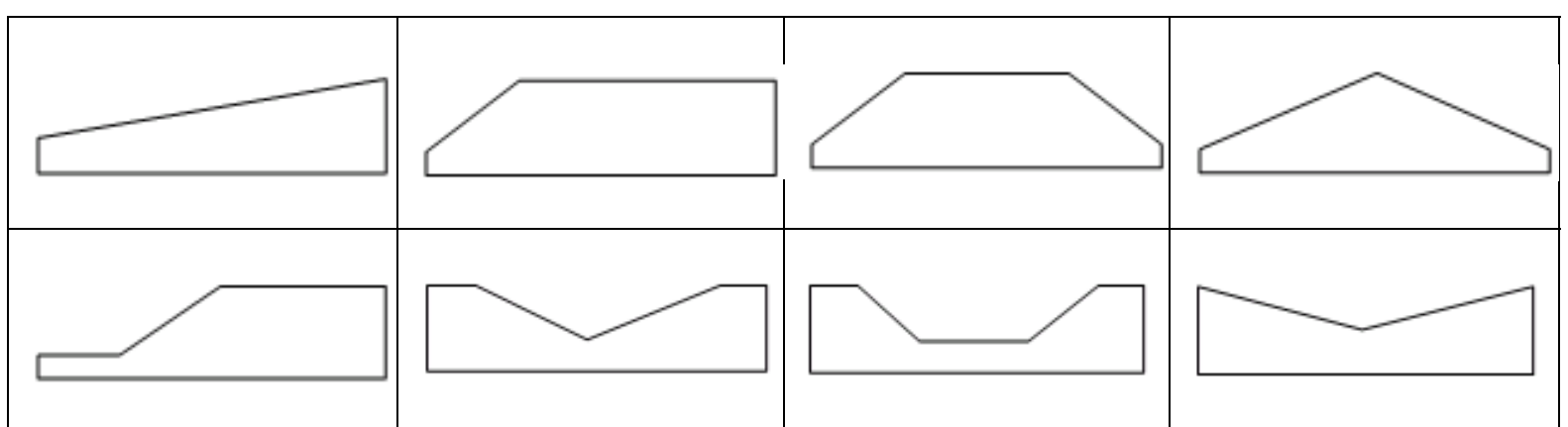

Figura 12 - Perfis possiveis de serem laminados

\subsection{MULPIC}

O equipamento de resfriamento de chapas - Mulpic ${ }^{\circledR}$ possui alta capacidade de extração de calor sendo capaz de realizar dois tipos de tratamento térmico: resfriamento acelerado e têmpera direta com grandes taxas de resfriamento. Todo processo é automatizado e controlado por um modelo matemático dedicado e integrado com a linha de laminação. O equipamento possui controle de vazão e resfriamento totalmente automáticos e recursos para obtenção de homogeneidade de temperatura e planicidade em todo o esboço. As principais inovações tecnológicas são: 
Mascaramento de borda (Edge Masking) e mascaramento de topo/base do esboço (Head/Tail Masking) controlados dinamicamente tendo como referência as informações do controle de tracking do material na linha. A figura 13, ilustra o funcionamento do Mascaramento de Borda e sua forma de atuação e a figura 14, ilustra a redução da vazão nas extremidades do esboço:

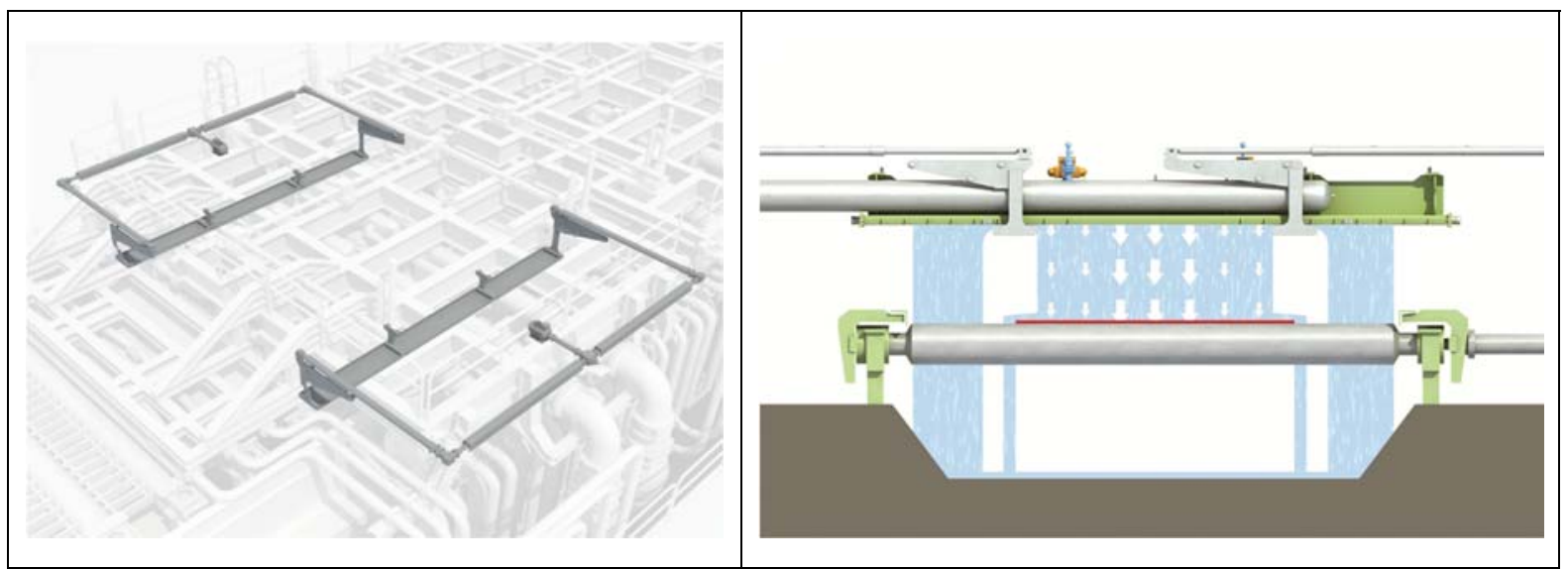

Figura 13 - Mascaramento de borda

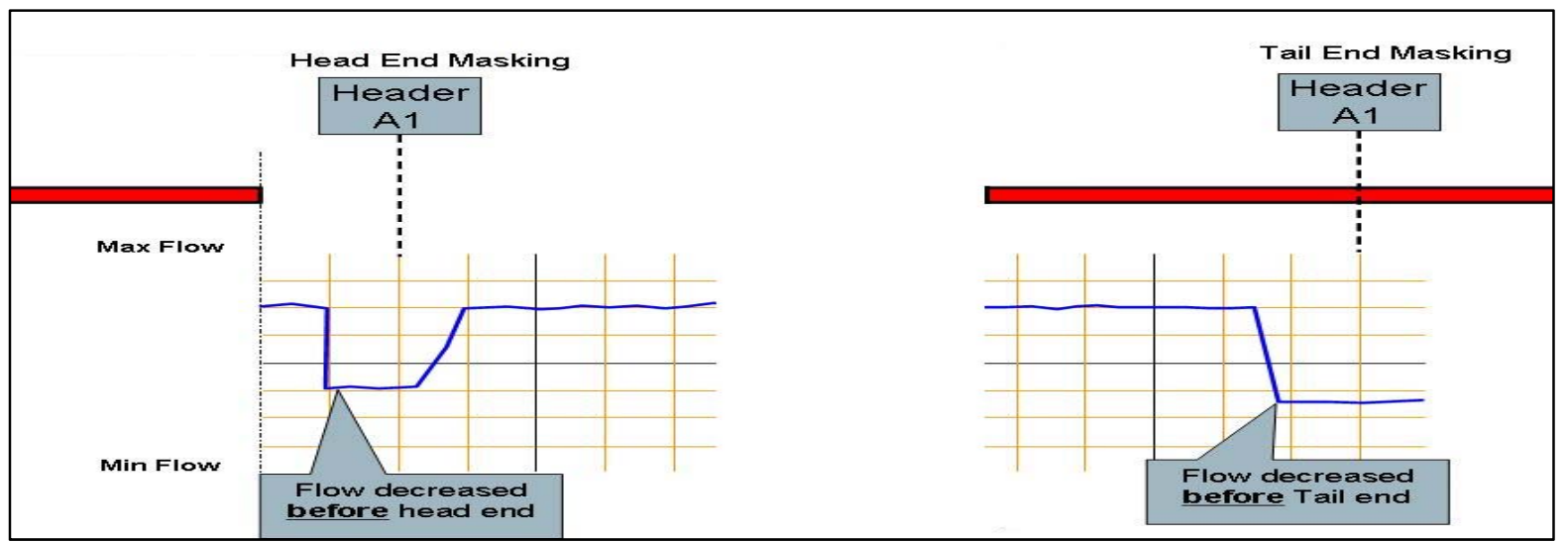

Figura 14 - Controle dinâmico das vazões dado o perfil de temperatura de entrada do Mulpic

A uniformidade de resfriamento ao longo do comprimento é capaz de ser obtido pelo Controle Feed Forward, onde as informações do Scanner de temperatura localizado na entrada da Pré Desempenadeira alimentam o modelo matemático para ajustar dinamicamente as vazões dos bancos considerando os pontos frios/quentes do esboço objetivando temperatura final de resfriamento constante; A figura 15 abaixo ilustra a variação de vazão ao longo do comprimento do laminado:

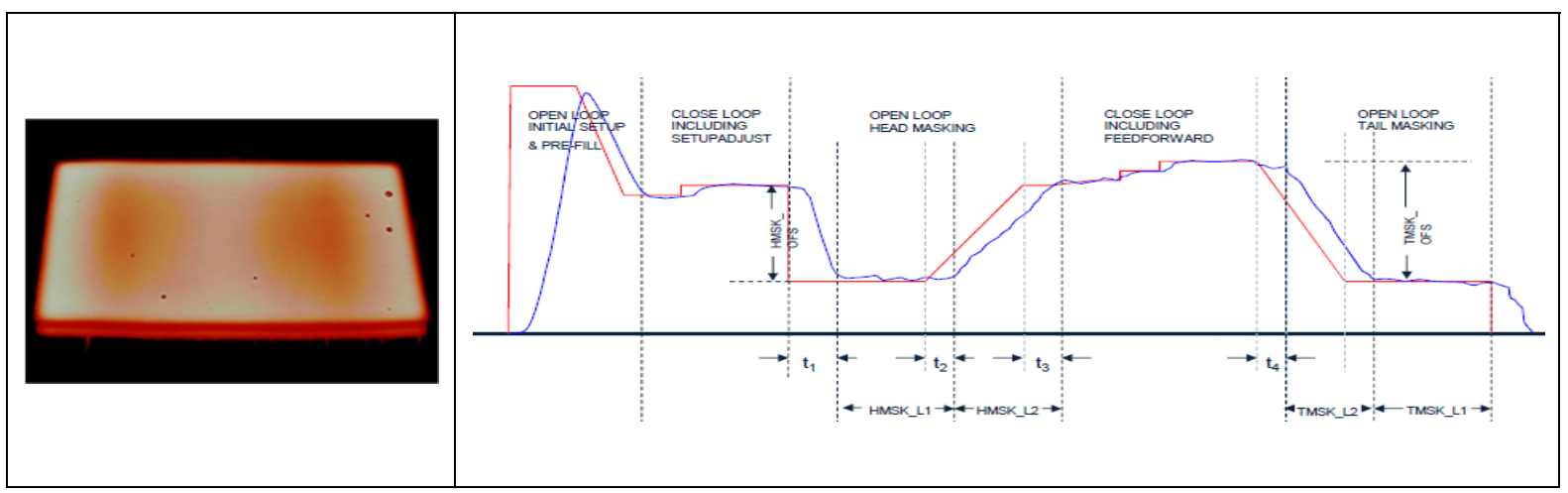

Figura 15 - Controle dinâmico das vazões dado o perfil de temperatura de entrada do Mulpic 
A uniformidade de resfriamento ao longo da largura é capaz de ser obtido pelo controle diferenciado de vazão ao longo dos headers. Os headers superiores estão divididos em três zonas no sentido da largura, uma zona central e duas zonas externas . O fluxo para as zonas externas são controladas com as válvulas de controle de coroamento d'agua. Isto significa que a distribuição do fluxo de água através do esboço é ajustável. As válvulas de controle de coroamento são de abertura variável e ajustáveis dinamicamente. A figura 16, ilustra a variação de vazão ao longo da largura do material e o design do header com a válvula de coroamento de água:

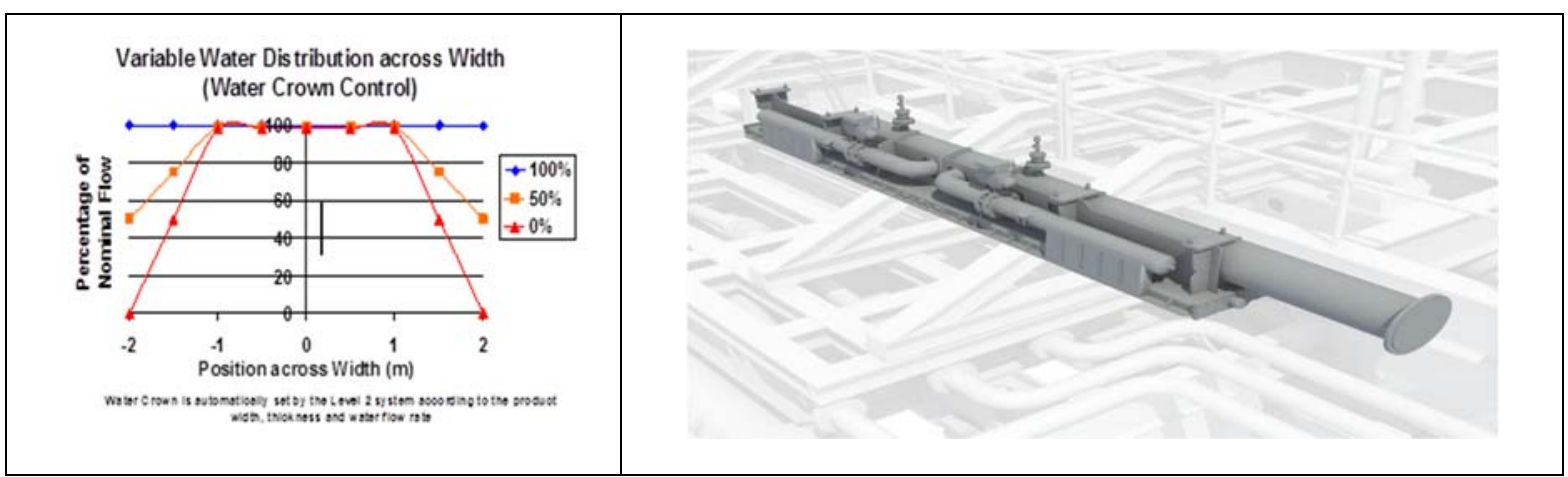

Figura 16 - Variação da vazão ao longo da largura e a válvula de coroamento d'agua

\subsection{DESEMPENADEIRA}

A desempenadeira a quente apresenta algumas características especiais, em função da maior resistência à quente dos materiais obtidos por laminação controlada: prédeflexão dos rolos superiores da desempenadeira, de modo a corrigir defeitos específicos de planicidade nos laminados, como ondulamento central, lateral, sistemas hidráulicos de abertura rápida em caso de sobrecarga e sistema simples para troca de rolos.

A implantação de processos combinados de laminação controlada/resfriamento acelerado elevou a resistência mecânica dos materiais a serem desempenados nesse equipamento. Em função desse problema foram adotadas duas abordagens: desempeno antes ou depois do resfriamento acelerado. Neste último caso torna-se necessário equipamentos mais robustos para se desempenar.

Todo material laminado é processado na desempenadeira a quente. O processo de desempeno a quente tem como objetivo corrigir as distorções de planicidade causadas durante os processos de laminação e resfriamento, tais como ondulações de borda e de centro. A desempenadeira a quente é composta de 6 rolos superiores e 5 inferiores e como todo equipamento da linha, possui um modelo matemático dedicado e integrado a linha de laminação. Possui recursos potentes para correção da planicidade:

O WRB - Work Roll Bending é um deles, pela ação de um cilindro hidráulico promove a manutenção do paralelismo dos rolos de trabalho, mantendo o gap constante ao longo do passe. Localizado no topo do equipamento, um cilindro hidráulico aplica uma força de deflexão ao cassete superior antecipando a flexão promovida pela força de desempeno.

A figura 17 mostra a localização do cilindro hidráulico do WRB e sua força de atuação: 

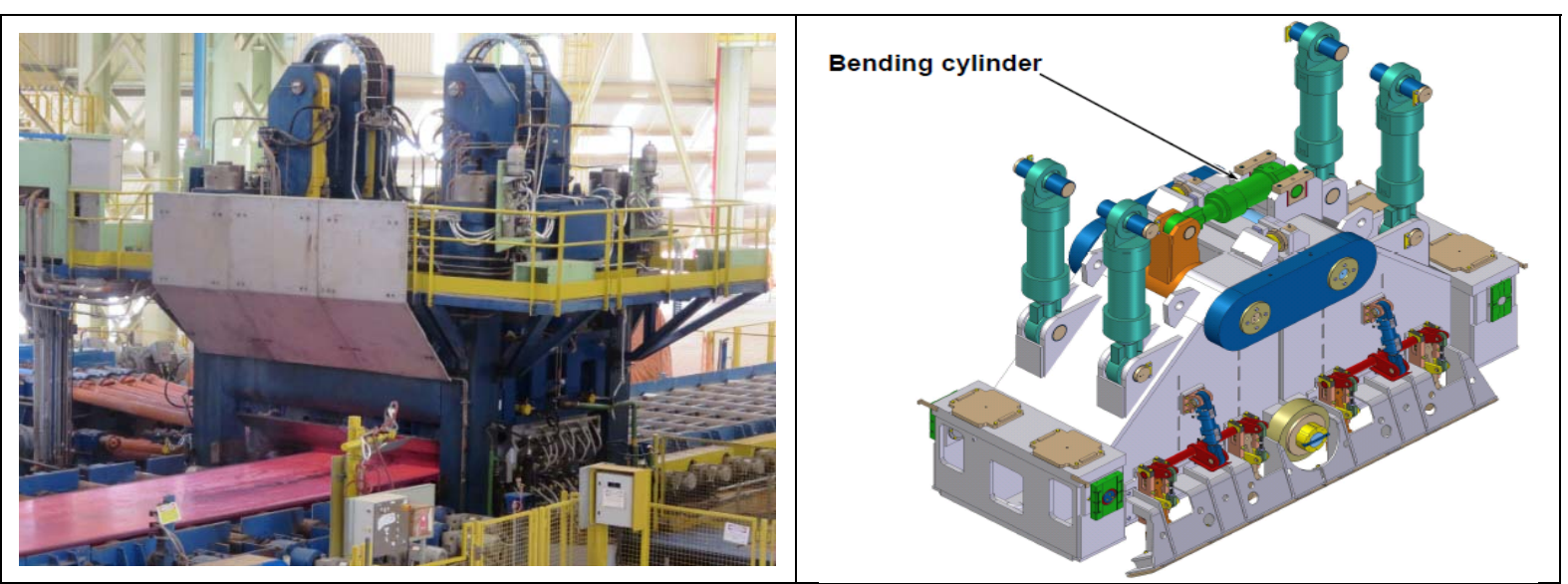

Figura 17 - Work Roll Bending da Desempenadeira a Quente

\section{CONCLUSÃO}

Este projeto é parte de um grande plano de investimentos da Gerdau visando aumentar seu portfólio de produtos. Devido ao elevado grau de automação e das novas tecnologias implantadas será possível a obtenção de produtos de grande valor agregado com excelente qualidade. Desta forma a Gerdau conquistará posição de destaque no mercado assim como já faz no segmento de bobinas a quente e produtos longos.

\section{REFERÊNCIAS}

1 Siemens VAI. Technical Specification for Plate Mill Plant for Gerdau Ouro Branco. 2010.

2 Laminação de Chapas Grossas da Gerdau. 2016. 